\title{
Numerical study on snow transport and drift formation
}

\author{
TAKAHIKO UEMATSU \\ Japan Weather Association, Kita-4 Nishi-23, Sapporo 064, Japan
}

\begin{abstract}
A three-dimensional, numerical simulation model for snow transport and drift formation is proposed in which saltation as well as suspension are considered as dynamic behavioral factors of moving snow particles. The procedure for simulation is as follows: (1) Air flow field is simulated solving the Reynolds equations and the continuity equation. (2) Using the result of the air field flow simulation, the blown-snow density field is simulated using the diffusion equations in which the fall velocity of blown snow particles is considered. In the boundary conditions, the particle movement of saltation is taken into consideration. (3) Finally, the snowdrift rate is computed based on the amount of snow particles not transported by saltation. This model was quantitatively tested for the phenomenon of snowdrift development. The computed results showed good agreement with observations.
\end{abstract}

\section{INTRODUCTION}

Uematsu and others (1989) tried to research drifting snow phenomena ranging from air flows to snowdrifts. Their models were two-dimensional except in the case of the suspension phenomenon. In this research the authors were not able to reproduce a snowdrift in a complicated topography, which points out the need for consideration of the suspension phenomenon. Recently there have been a few papers on this topic, but none of much significance. No numerical simulations have considered the air flows which lead to drifting snow as well as both the saltation and the suspended motion of snow particles.

\section{NUMERICAL MODEL}

\section{Basic equations}

\section{Air flow}

Snowdrift development is mainly controlled by the friction velocity $u_{*}$, which can be obtained from a velocity profile.

A numerical simulation method developed by Arisawa (1987) is applied to obtain a three-dimensional velocity field. Arisawa's method is a so-called control volume method based on Patanker's algorithm (Patanker, 198i). The Reynolds equations with boundary conditions are numerically solved using this method.

\section{Snow transport}

Snow transport is possible by saltation, suspension or creep. As mentioned above, only saltation and suspension are taken into consideration in this simulation.

Up to now, many empirical formulae describing snowdrift transport rate by saltation have been issued (e.g. Kobayashi, 1972). However, the application of these empirical formulae are limited strictly to the place and time of the observation because they contain empirical constants. Therefore, in view of future applications, a new theoretical equation should be derived from the particle trajectory.

Assuming that the saltation phenomenon occurs continuously, the following four equations for saltation of snow particles are derived. The parameters used in the derivation of the trajectory of saltating particles are shown in Figure 1.

The shear stress $\tau_{0}$ at the snow surface is expressed by the following formula

$$
\tau_{0}=\tau_{\mathrm{S} 0}+\tau_{t}
$$

where $\tau_{\mathrm{S} 0}$ is the shear stress caused by collision of saltating particles with the surface and $\tau_{t}$ is the shear stress due to wind. Here, $\tau_{t}$ is assumed to be the critical shear stress, which is consistent with the assumption of Owen (1964).

$\tau_{\mathrm{S} 0}$ can be expressed as

$$
\tau_{\mathrm{S} 0}=M\left(U_{2}-U_{1}\right),
$$

where $M$ is the mass flux per unit area and time, $U_{2}$ is the horizontal component of the particle velocity before collision with the surface, and $U_{1}$ is the horizontal component of the particle velocity after collision. The

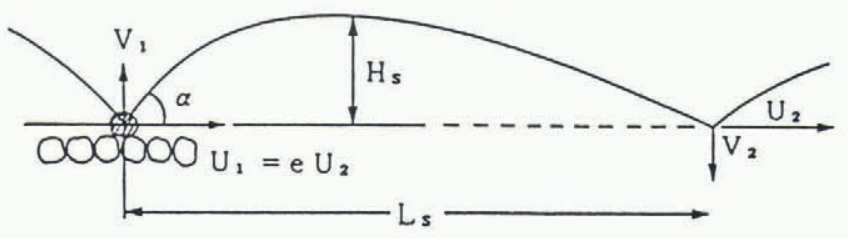

Fig. 1. Sketch for the definition of trajectory parameters. 
condition for snow particles undergoing constant saltation can be given by the equation

$$
\frac{M}{m}=\frac{N}{L_{\mathrm{S}}}
$$

Here, $m$ is the mass of a single particle given by $(\beta / 6) \pi d^{3}$, $d$ is the diameter of the particle and $\beta$ is the density of ice. $N$ is the number of particles passing per unit width per unit time, and $L_{\mathrm{S}}$ is the saltation length. The lefthand side of Equation (1.3) gives the number of particles passing per unit area per unit time, and the righthand side gives the number of particles landing on the surface.

Finally, the snowdrift transport rate $q_{\mathrm{B}}$ is defined as

$$
q_{\mathrm{B}}=N m \text {. }
$$

Using Equations (1.1), (1.2), (1.3) and (1.4), the following theoretical equation for particle transport rate can be derived:

$$
q_{\mathrm{B}}=\frac{e}{1-e} \frac{\tan \alpha}{\sqrt{\frac{2 H_{\mathrm{S}}}{L_{\mathrm{S}}}}} \sqrt{S+\frac{3}{2}} \frac{u_{*}^{2}-u_{* t}^{2}}{\sqrt{S g d}} \sqrt{L_{\mathrm{S}}} d \rho .
$$

Here, $H_{\mathrm{S}}$ is the saltation height, $\alpha$ is the fly-out angle, $e$ is the restitution coefficient, $S=/ \rho-1, g$ is the acceleration due to gravity, and $u_{* t}$ is the threshold friction velocity. Although there are many variables in Equation (1.5), each has a physical meaning.

Equation (1.5) is checked in section 3 by comparison with observations. The values for $L_{\mathrm{S}}, H_{\mathrm{S}}, d$ and $e$ are given as follows: $e=0.8$, obtained from the collision experiment on the ice particles against the ice surface (Araoka and Maeno, 1978); the other three are constant values since $L_{\mathrm{S}}$ is a function of a friction velocity, judging from the work of Kikuchi (1981). As a result, Equation (1.5) is reduced to

$$
q_{\mathrm{B}}=7.404 \rho \sqrt{d}\left(u_{*}^{2}-u_{* t}^{2}\right) u_{*} .
$$

Equation (1.6) is compared with the data collected by Kobayashi (1972). Figure 2 shows that this semitheoretical equation compares well with measured values.

Suspension is modeled using the diffusion equation.

The deposition (or erosion) rate can be calculated by simulating the drift density $\Phi_{\mathrm{h}}$ in the saltation layer. The deposition rate, $d$, can be expressed as

$$
d=\left|w_{\mathrm{f}}\right| \Phi_{\mathrm{h}} .
$$

Here, $w_{\mathrm{f}}$ is the snowfall velocity. In Equation (1.7) the maximum erosion rate is assumed to be equal to the maximum deposition rate.

The maximum erosion rate, $e_{\mathrm{r}}$, can be expressed as

$$
e_{\mathrm{r}}=\frac{q\left|w_{\mathrm{f}}\right|}{u_{\mathrm{h}} h} .
$$

Finally, we can calculate the snowdrift rate, $s$, as

$$
s=-\left(d+e_{\mathrm{r}}\right),
$$

where $s$ is defined as the mass of snow accumulation on a unit horizontal area per unit time.

\section{Numerical aspects}

Various methods for numerical calculation in fluid

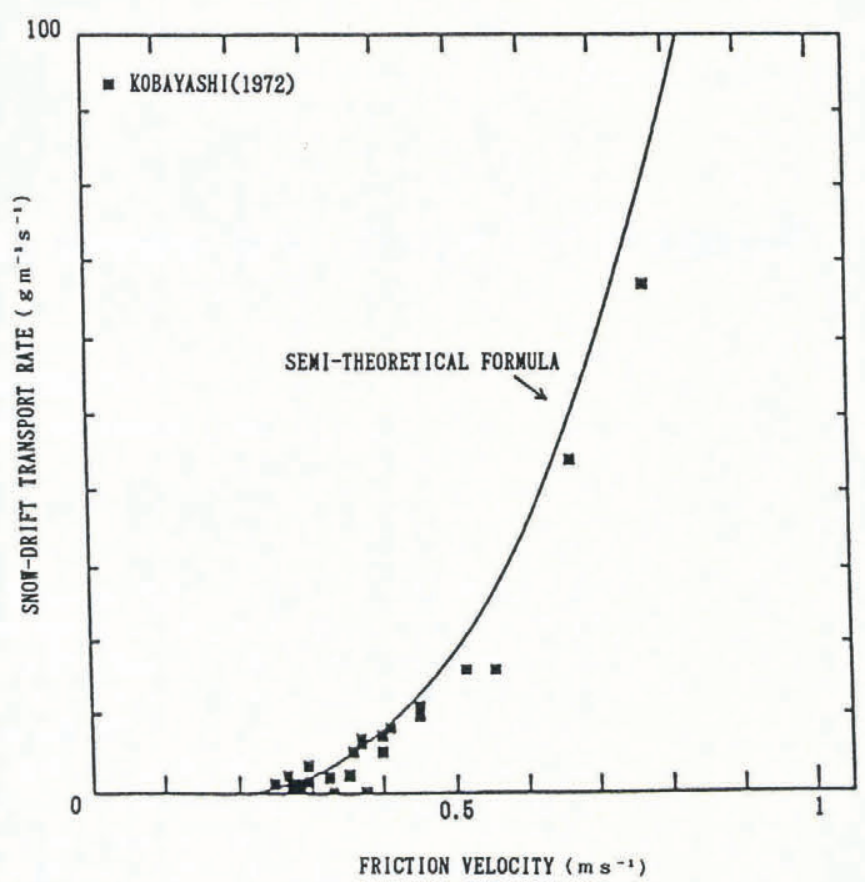

Fig. 2. Snowdrift transport rate against friction velocity by Kobayashi (1972) and the simulated curve of the semitheoretical formula.

mechanics are found in Roache's textbook (1978). Among them, the "control volume method" is presumed to be the most physically precise. The SIMPLER (SemiImplicit Method for Pressure-Linked Equations Revised) model, which Patanker (1981) proposed, is used here.

\section{Initial and boundary conditions}

This simulation is roughly divided into two parts, flow and snowdrift density. Each initial and boundary condition is applied here. To determine the snowdrift density, the diffusion equation must be solved. In doing so, setting the boundary and initial conditions becomes a problem.

Air flow

The boundary conditions are now stated.

At the lower boundary

$$
u=v=w=0 .
$$

At the top of the domain

$$
u=u_{0}, v=v_{0}, w=0,
$$

and

$$
\rho=(\rho)_{t=0},
$$

where $u_{0}$ and $v_{0}$ are the initial wind speeds at the top of the domain and $(\rho)_{t}$ is the initial air density.

At the lateral boundaries, the radiation condition of Orlanski (1976) is adopted.

The logarithmic distribution is adopted as the initial condition over the entire domain.

\section{Snow transport}

The lower boundary of the suspension layer is in contact with the saltation layer; therefore, the mean snowdrift 
density of the saltation layer is considered to be the lower boundary condition.

Strictly speaking, the height of the saltation layer varies with the degree of development of the snowdrift; however, it is assumed to be approximately constant at all points.

The snowfall rate is used as the upper boundary condition for suspension. The upper boundary of suspension is the height where the snowdrift density becomes zero. The upper boundary condition is expressed as

$$
\Phi_{\mathrm{H}}=\frac{P_{\mathrm{re}}}{\left|w_{\mathrm{f}}\right|},
$$

where $P_{\mathrm{re}}$ is the snowfall rate.

The snowdrift density $\Phi_{\mathrm{H}}$ is used as the initial condition over the entire domain.

\section{The other variables}

The five elements shown in Table 1 are input values for the other variables in the numerical simulation. The wind speed and snowfall rate are explained as the initial condition (described above). The roughness height is used to give the initial condition for air-flow calculation and at the same time to acquire the friction velocity on the snow surface from the wind-speed distribution obtained. The threshold friction velocity is used to acquire the driftingsnow transport rate of the saltation layer. Furthermore, the falling velocity is used to convert snowfall rate and the drifting-snow transport rate into the snowdrift density.

\section{Flowchart of simulation}

Figure 3 outlines the flow of the calculation process. First, geographical features are taken as a boundary for the calculation of air flow. The calculation of air flow is repeated until the wind velocity given by the logarithmic distribution converges.

Next, the snowdrift density is calculated using the previously obtained air flow. The calculations are repeated until a converged value is obtained using the snowdrift density obtained from snowfall rate for the initial condition. As a result, the snowdrift density and the snowdrift rate are obtained. A snowdrift is simulated by integrating the snowdrift rate. A snowdrift at an arbitrary time can be obtained by repeating the above calculation for a necessary period of time.

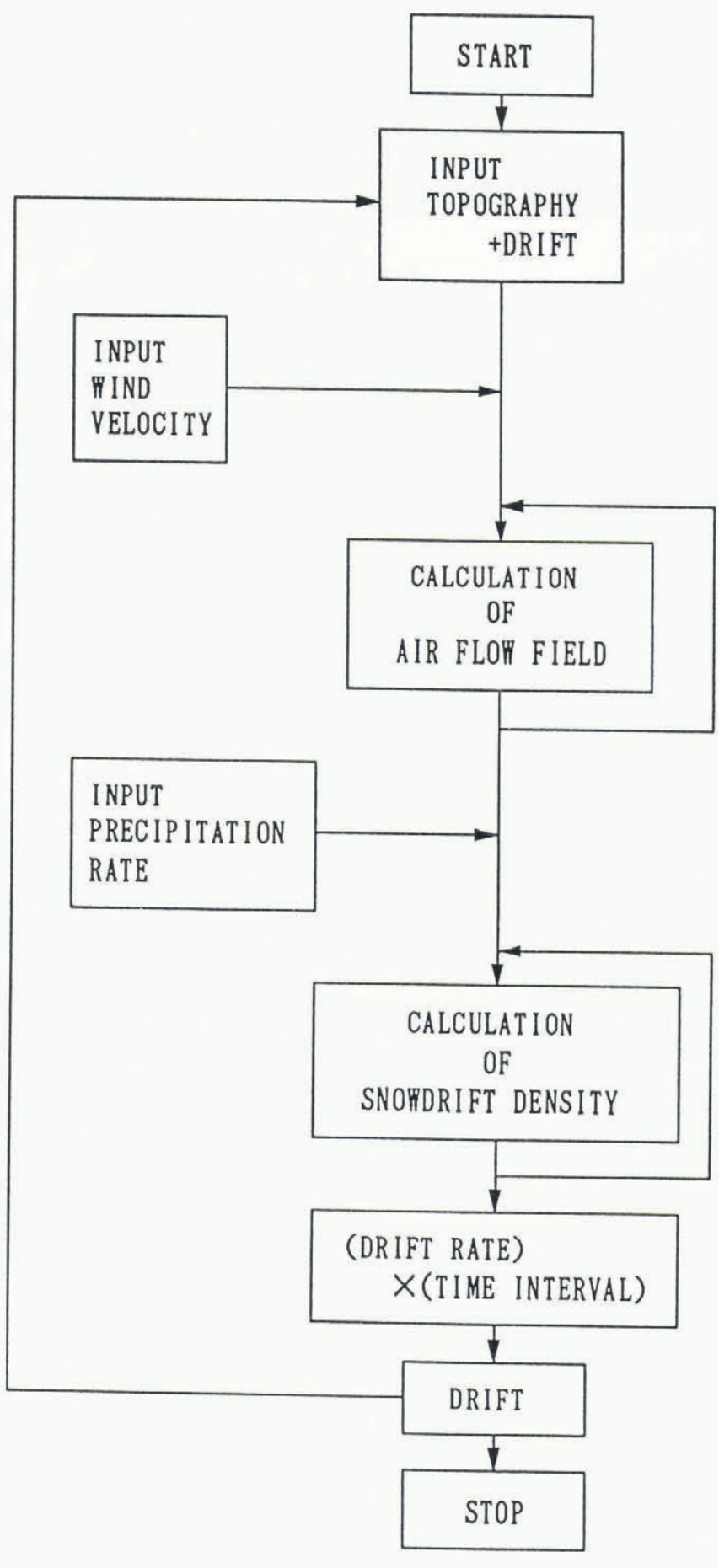

Fig. 3. Flowchart of simulation.

Table 1. Input data

$\begin{array}{llll}\text { Input data Diameter Diameter } & \text { References }\end{array}$

$$
\mathrm{d}=0.3 \mathrm{~mm} \quad \mathrm{~d}=0.1 \mathrm{~mm}
$$

Windspeed

Roughness height

Threshold speed

Snowfall velocity

Precipitation rate observational data

$\begin{array}{llll}0.1 \mathrm{~mm} & 0.08 \mathrm{~mm}^{-1} & 0.03 \mathrm{~mm}^{-1} & \text { Lettau (1969) } \\ 0.20 \mathrm{~m} \mathrm{~s}^{-1} & 0.29 \mathrm{~m} \mathrm{~s}^{-1} & 0.17 \mathrm{~m} \mathrm{~s}^{-1} & \text { White (1940) } \\ 0.50 \mathrm{~m} \mathrm{~s}^{-1} & 0.65 \mathrm{~m} \mathrm{~s}^{-1} & 0.22 \mathrm{~m} \mathrm{~s}^{-1} & \text { Kawamura (19 } \\ \text { rvational data } & & & \end{array}$

$0.22 \mathrm{~m} \mathrm{~s}^{-1}$

Kawamura (1982) 


\section{COMPARISON OF SIMULATION WITH OBSERVATION}

The above method enables us to simulate a variety of snowdrift cases. In this section, the results of the simulation are compared with the observations of the past. The result of drifting snow simulation on a plain is described because it has the simplest topographical setting among those analyzed, and much research of drifting snow has been conducted for this case.

Figure 4 shows the mesh used for the calculation, the snowdrift density $\left(\mathrm{g} \mathrm{m}^{-3}\right)$, and the snowdrift rate $\left(\mathrm{g} \mathrm{m}^{-2}\right.$ $\mathrm{s}^{-1}$ ). The horizontal axis shows the distance from the origin of the snowdrift, and the vertical axis shows the height above the snow surface. Figure $4 \mathrm{a}$ is the case for a particle diameter of $0.3 \mathrm{~mm}$, and Figure $4 \mathrm{~b}$ for the particle diameter of $0.1 \mathrm{~mm}$. The area of oblique lines in the drift-density graph shows where the snowdrift density is greater than the snowfall density. Figure $4 \mathrm{a}$ and $4 \mathrm{~b}$ shows that the snowdrift density becomes larger leeward from the origin of the snowdrift and decreases gradually as the depth increases. The depth of the high-drift density

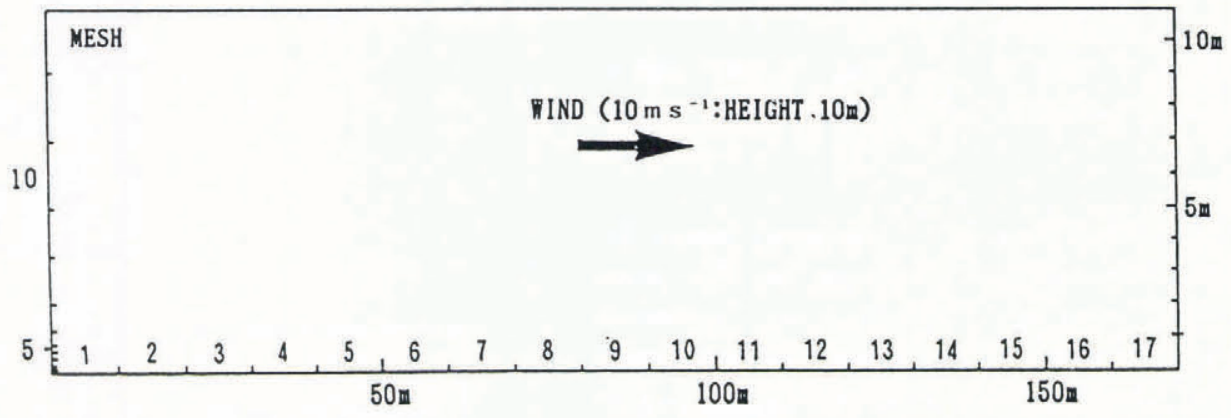

DRIFT DENSITY $\left(\mathrm{g} \mathrm{m}^{-3}\right)$

DIAMETER $0.3 \mathrm{ma}$

PRECIPITATION RATE $1 \mathrm{~mm} / \mathrm{hr}$

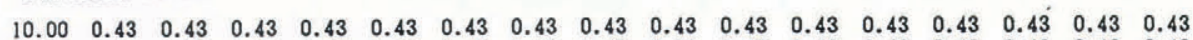
$\begin{array}{lllllllllllllllll}8.00 & 0.43 & 0.43 & 0.43 & 0.43 & 0.43 & 0.43 & 0.43 & 0.43 & 0.43 & 0.43 & 0.43 & 0.43 & 0.43 & 0.43 & 0.43 & 0.43\end{array}$ $\begin{array}{lllllllllllllllll}6.00 & 0.43 & 0.43 & 0.43 & 0.43 & 0.43 & 0.43 & 0.43 & 0.43 & 0.43 & 0.43 & 0.43 & 0.43 & 0.43 & 0.43 & 0.43 & 0.43\end{array}$

$\begin{array}{llllllllllllllllll}\text {. } & 4.25 & 0.43 & 0.43 & 0.43 & 0.43 & 0.43 & 0.43 & 0.43 & 0.43 & 0.43 & 0.43 & 0.43 & 0.43 & 0.43 & 0.43 & 0.43 & 0.43\end{array}$ $\begin{array}{lllllllllllllllll}2.75 & 0.43 & 0.43 & 0.43 & 0.43 & 0.43 & 0.43 & 0.43 & 0.43 & 0.43 & 0.43 & 0.43 & 0.43 & 0.43 & 0.43 & 0.43 & 0.43\end{array}$

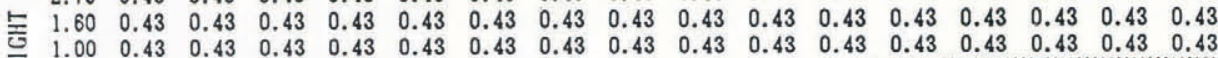

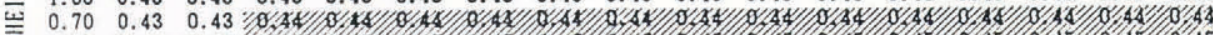

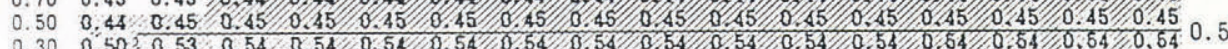

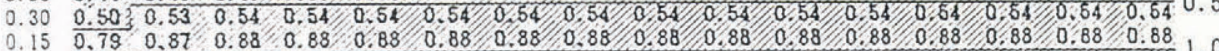

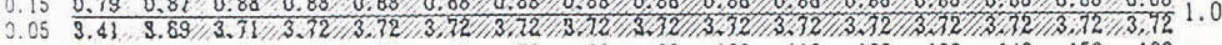
$\begin{array}{llllllllllllllll}10 & 20 & 30 & 40 & 50 & 60 & 70 & 80 & 90 & 100 & 110 & 120 & 130 & 140 & 150 & 160\end{array}$ I DISTANCE (iv)
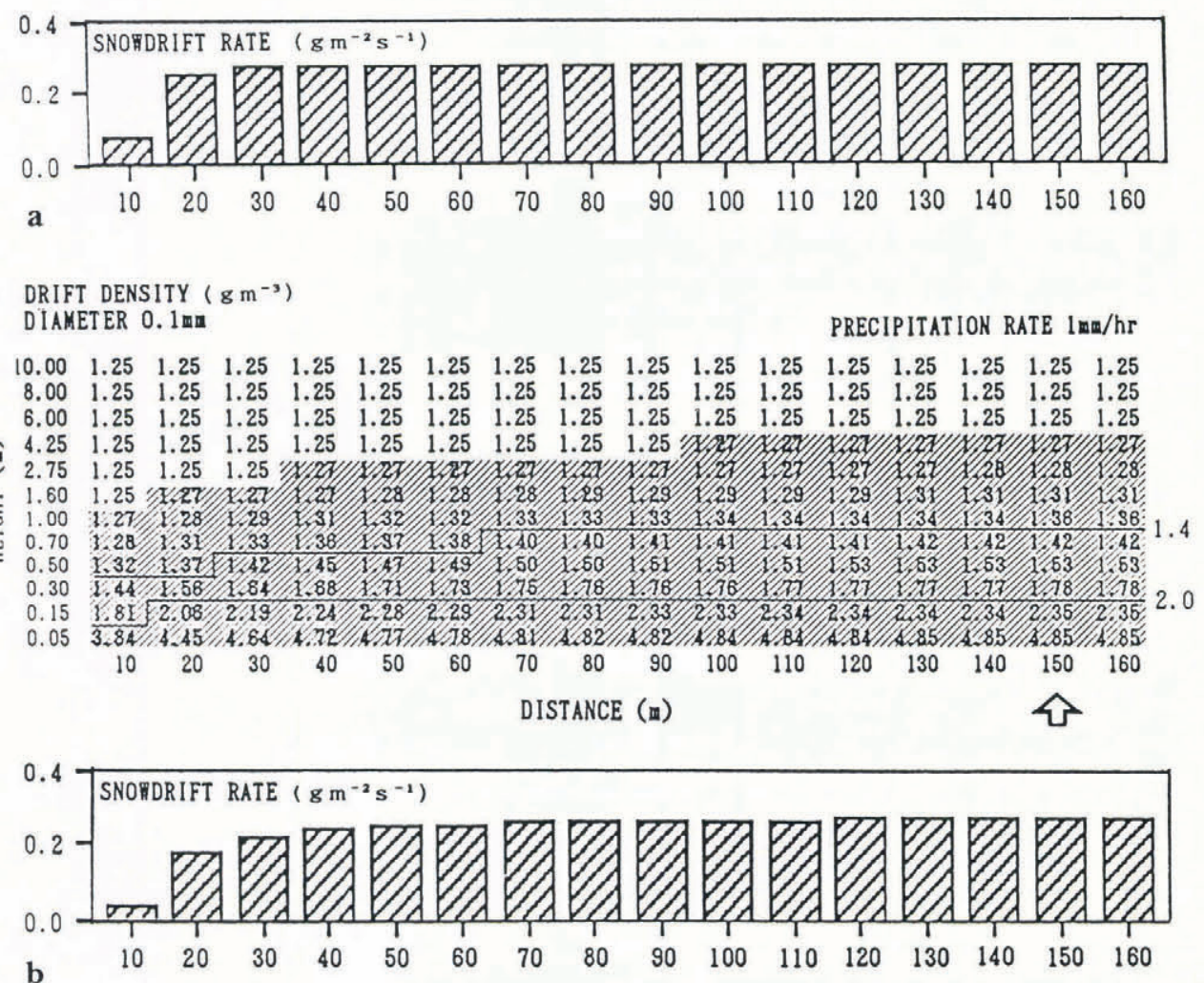

Fig. 4. Calculated drift density and snowdrift rate in a plain with wind velocity of $10 \mathrm{~m} \mathrm{~s}^{-1}$ at height of $10 \mathrm{~m}$ above snow surface. (a) Snow particle diameter is $0.3 \mathrm{~mm}$. (b) Snow particle diameter is $0.1 \mathrm{~mm}$. 


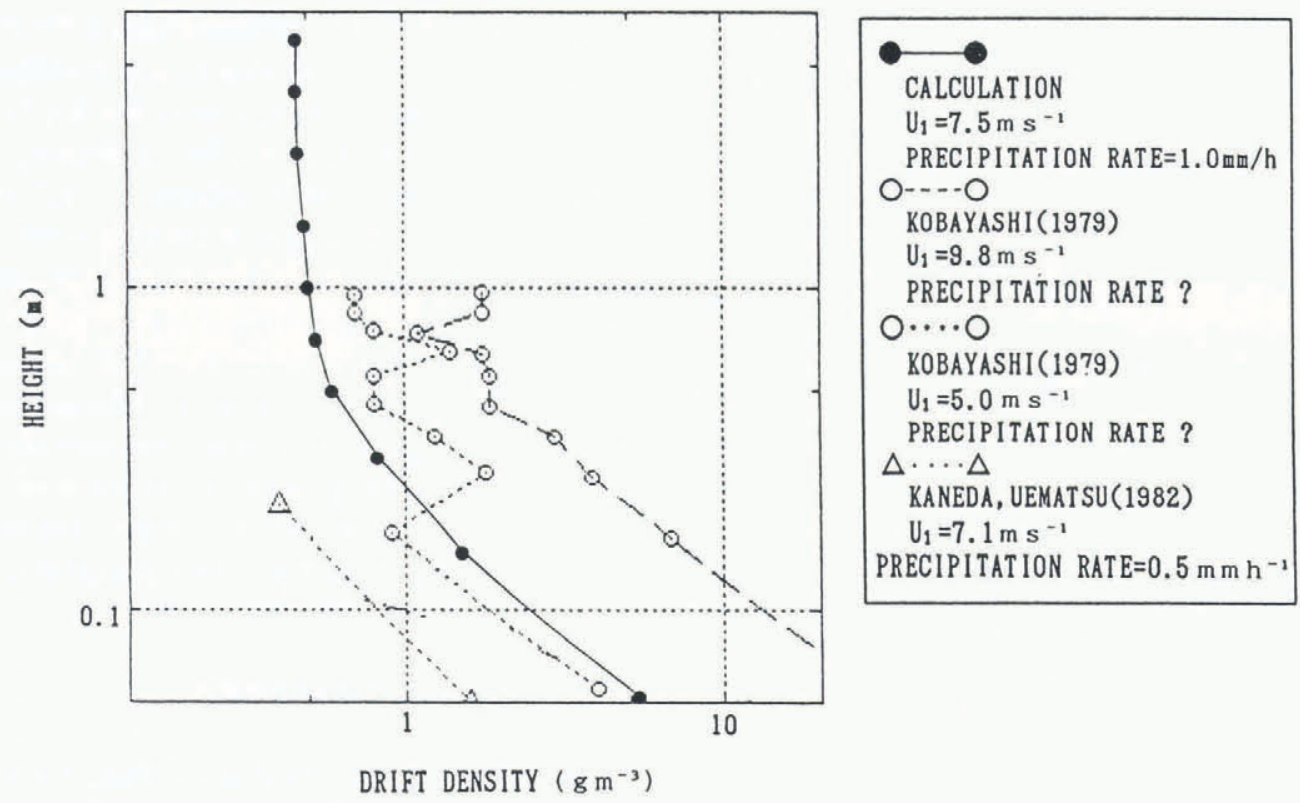

Fig. 5. Comparison between observed and simulated drift density.

layer is $0.7 \mathrm{~m}$ for a particle diameter of $0.3 \mathrm{~mm}$, and $4.25 \mathrm{~m}$ for that of $0.1 \mathrm{~mm}$. There is almost no change in the height and density of the high-drift density layer. The windward lateral boundary is $40 \mathrm{~m}$ from the origin of the snowdrift for the particle diameter of $0.3 \mathrm{~mm}$, and $110 \mathrm{~m}$ for that of $0.1 \mathrm{~mm}$. For both particle diameters, the leeward snowdrift rate increases gradually from zero to the snowfall rate towards leeward. The snowdrift rate reaches the snowfall rate at approximately the same point that the drift density becomes constant.

Figure 5 shows the drift-density profile, which was obtained at steady state. The solid circles show the simulation result and the other symbols show observations from the past. The drift density decreases nearly linearly up to a height of $50 \mathrm{~cm}$, and becomes constant above $50 \mathrm{~cm}$ with the logarithmic vertical axis. This profile is compared with the observations of Kobayashi (1979), and Kaneda and Uematsu (1982) (Fig. 6). The simulated profile falls between the density profiles for wind speeds of $9.8 \mathrm{~m} \mathrm{~s}^{-1}$ and $5.0 \mathrm{~m} \mathrm{~s}^{-1}$ at the height of $1 \mathrm{~m}$ above the snow surface (Kobayashi, 1979). Since the simulation was done for a wind speed of $7.5 \mathrm{~ms}^{-1}$, the result is considered adequate.

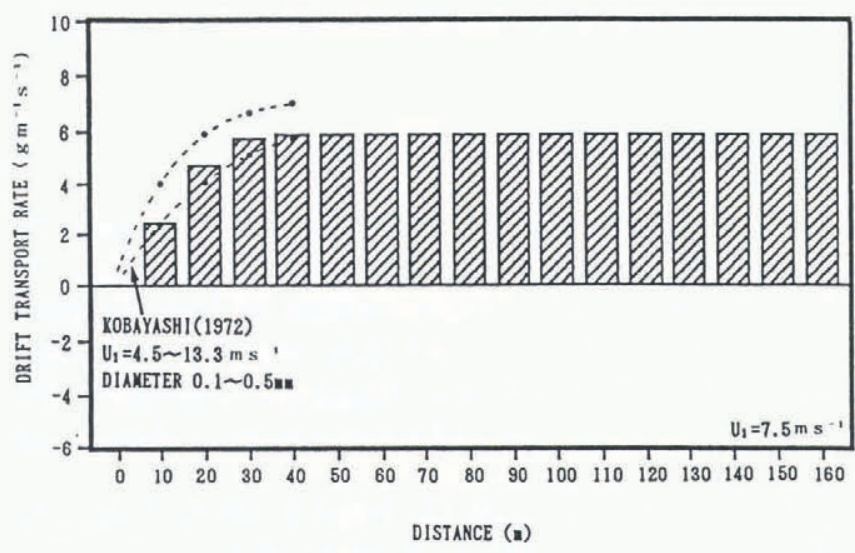

Fig. 6. Comparison between observed drift transport rate (Kobayashi (1972)) and simulated rate.
Figure 6 shows the variation of snowdrift transport rate relating to the distance from the origin of the snowdrift. The snowdrift transport rate increases in the leeward direction and becomes constant for $30 \mathrm{~m}$ and beyond. This tendency is consistent with the observations of Kobayashi (1972), which were obtained at wind speeds of $4.5-13.3 \mathrm{~m} \mathrm{~s}^{-1}$ at $1 \mathrm{~m}$ above snow surface with particle diameters of $0.1-0.5 \mathrm{~mm}$. Thus, this newly developed model agrees well with past observations. Takeuchi (1980a) observed that snow transport rate becomes constant $350-400 \mathrm{~m}$ from the origin of the snowdrift while Kobayashi (1972) observed that point to be 30$60 \mathrm{~m}$ from the origin. This contradiction may be explained by the difference in particle diameter, as shown above.

\section{DISCUSSION}

The theoretical formula of the snowdrift transport rate by saltation is examined first. Equation (1.5) for the snowdrift transport rate by saltation contains the following coefficients and constants: saltation distance; saltation height; angle of departure; restitution coefficient; diameter of snow particle; air density; density of snow particle; friction velocity; and thereshold friction velocity at which the snow particles begin to move. It is important to know which coefficients or constants make a main contribution to the snowdrift transport rate.

First, the ratio of the saltation height to the saltation length ranges from 0.1 to 0.4 as shown in Figure 7; therefore, the snowdrift transport rate ranges from 1.6 to 3.1 . Next, the angle of departure is roughly in the range from $20^{\circ}$ to $80^{\circ}$, and the transport rate varies from 0.4 to 5.6. Moreover, the diameter of the snow particle is in the range of $0.1-0.5 \mathrm{~mm}$, reported by Kobayashi (1972), and the snowdrift transport rate varies from 0.01 to 0.02 . The coefficient of restitution for the snow particle and the ice surface is roughly in the range of $0.2-0.9$ by Araoka and Maeno (1978), therefore, the snowdrift transport rate 

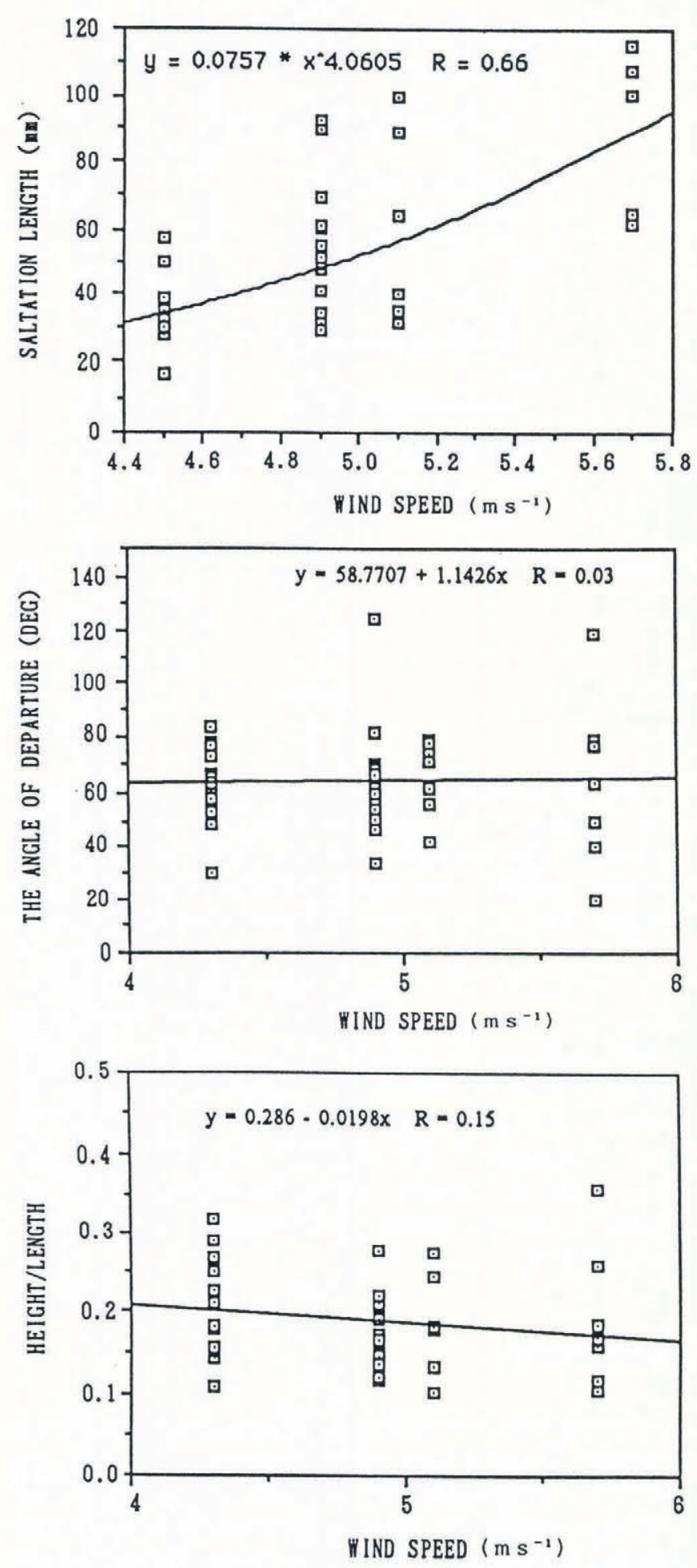

Fig. 7. Saltation length, angle of departure and the ratio of saltation height to saltation length against wind speed, obtained by the wind tunnel experiment (Kikuchi, 1981).

varies from 0.25 to 9.0 . The threshold friction velocity calculated with the diameter of the particle by White's formula (1940) is in the range of $0.2-0.4 \mathrm{~m} \mathrm{~s}^{-1}$, and the snowdrift transport rate ranges from 0.04 to 0.16 . The friction velocity is in the range of $0.2-1.0 \mathrm{~m} \mathrm{~s}^{-1}$, and the snowdrift transport rate varies from 0.04 to 1.0 . When the maximum value of the contribution is divided by the minimum value, the resultant value indicates the degree of change in the snowdrift transport rate. The resulting ratios are: 1.9 for the ratio of saltation height to saltation length; 14 for the angle of departure; 2 for the diameter of the particle; 4.5 for the restitution coefficient; 4 for the threshold friction velocity; and 25 for the friction velocity. These values for the friction velocity, the angle of departure, restitution coefficient, and the threshold friction velocity are larger than 4; however, the angle of departure as well as the restitution coefficient are distributed near the average values as shown in Figure 7 and do not influence the snowdrift transport rate. On the other hand, the range of the friction velocity is very common, as reported by many researchers. Its accuracy must influence the presumed accuracy of the snowdrift transport rate. Therefore, it is important to compute the friction velocity precisely in this simulation model.

\section{CONCLUDING REMARKS}

In this study, a numerical simulation model was applied to the drifting snow and snowdrift phenomena. The following results were obtained:

A new theoretical expression for the saltation movement of snow particles is derived from the ballistic study, and thereby, the amount of drifting snow transport in the saltation layer is calculated. The computational results show good agreement with an observed result.

A three-dimensional numerical simulation model is developed for drifting snow and snowdrifts. The simulated flow is determined as follows: (1) Air flow is obtained by solving Reynolds equation and the continuity equations. (2) Using the airflow obtained, the diffusion equation is solved by introducing a semitheoretical expression of saltation for a lower boundary condition. (3) From the computed solution of the diffusion equation, the accumulation of snow is defined as those snow particles that are not transported by saltation.

The developed numerical model was applied to the drifting snow phenomena on level ground.

Various observed snowdrifts were reproduced using this model. In the case where the snowdrift itself changes physical conditions of the air flow, the model is run repeatedly, giving the newly formed drifting snow surface as the lower boundary.

\section{ACKNOWLEDGEMENTS}

I wish to express my thanks to Drs D. Kobayashi, N. Maeno, N. Ishikawa, R. Narue, K. Nishimura, Y. Kodama and Y. Ishii of the Institute of Low Temperature Science, Hokkaido University, and Dr K. Chikita, Department of Geophysics, Hokkaido University, for their helpful discussions and encouragement throughout this study.

I am also grateful to Mr Y. Arisawa, Mr K. Takeuchi, Mr T. Nakata and Mr T. Kaneda of Japan Weather Association for their helpful assistance. I am indebted to Ms Y. Yamada, Japan Weather Association, for her 
assistance in preparing the manuscript. Finally, I also sincerely thank Mr H. Denpo, Mr M. Yamazaki and Mr M. Satake, Japan Weather Association, for their encouragement.

This paper is the abstract of a Ph.D. thesis, Hokkaido University, 1992.

\section{REFERENCES}

Araoka, K. and N. Maeno. 1978. Measurements of restitution coefficients of ice. Low Temp. Sci., Ser. A 36, 55-65. [In Japanese with English summary.]

Arisawa, Y. 1987. Two-dimensional numerical experiments on the mechanism of long-range transport of air pollution. (Ph.M. thesis, University of Tsukuba.)

Kaneda, Y. and T. Uematsu. 1982. Research report on snowbreak forest in Do-o highway. Sapporo, Japan Highway Public Corporation. Iwamizawa Construction Office. Sapporo Construction Bureau. [In Japanese.]

Kawamura, S. 1982. Earth and sand hydraulics 1. Moritita Shuppan.

Kikuchi, T. 1981. Studies on aerodynamic surface roughness associated with drifting snow. Mem. Fac. Sci. Kochi Univ., Ser. B, 2, 13-37.

Kobayashi, D. 1972. Studies of snow transport in lowlevel drifting snow. Contrib. Inst. Low Temp. Sci., Ser. A 24.
Kobayashi, S. 1979. Studies on interaction between wind and dry snow surface. Contrib. Inst. Low Temp. Sci., Ser. A 29.

Lettau, H. 1969. Note on aerodynamic roughnessparameter estimation on the basis of roughnesselement description. F. Appl. Met., 8, 828-832.

Orlanski, I. 1976. A simple boundary condition for unbounded hyperbolic flows. F. Comput. Phys., 21, 251269.

Owen, P. R. 1964. Saltation of uniform grains in air. F. Fluid Mech., 20(2), 225-242.

Patanker, S. V. 1981. Numerical heat transfer and fluid flow. Hemisphere Pub.

Roache, P.J. 1978. Computational fluid dynamics. Kozokeikaku Engineering Inc. [In Japanese.]

Takeuchi, M. 1980. Research on visibility in blowing snow. Report of the Civil Engineering Research Institute 74, $1-31$.

Uematsu, T., Y. Kaneda, K. Takeuchi, T. Nakata and M. Yukumi. 1989. Numerical simulation of snowdrift development. Ann. Glaciol., 13, 265-267.

White, C. M. 1940. The equilibrium of grains on the bed of a stream. Proc. R. Soc. London, Ser. A, 174(958), 322338.

The accuracy of references in the text and in this list is the responsibility of the author, to whom queries should be addressed. 